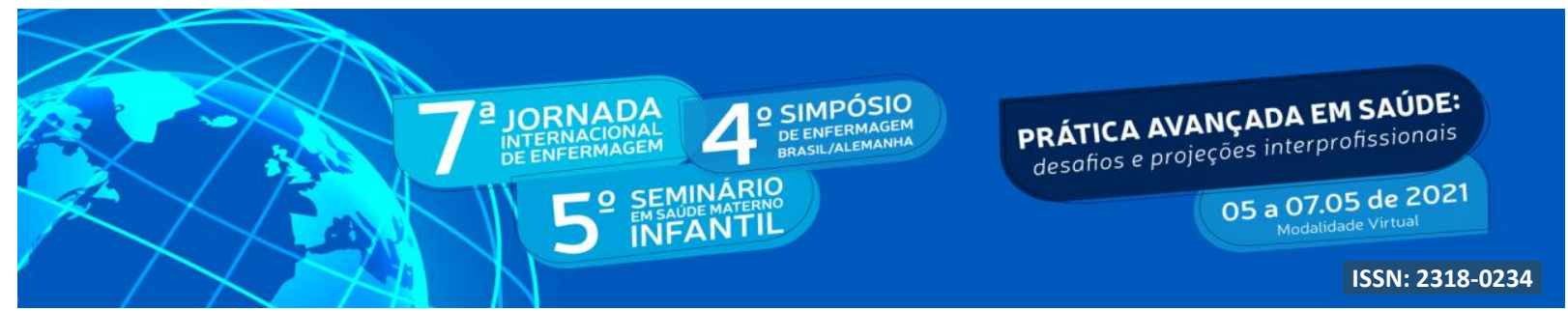

DOI: http://doi.org/10.48195/jie2021-117

\title{
A RADIAÇÃO SOLAR ESTÁ INTIMAMENTE LIGADA AO CÂNCER DE PELE
}

\author{
Gabriela Haas de Mello' ${ }^{1}$ Francine Carla Cadoná ${ }^{2}$
}

\begin{abstract}
RESUMO
O trabalho teve como objetivo mostrar o aumento do número de casos de câncer (CA) de pele, além de trazer os principais fatores desencadeantes da doença. Os quais podem estar diretamente relacionados com fatores genéticos e externos, à exposição solar sem os devidos cuidados é apontada como um dos principais fatores de risco. A exposição à radiação ultravioleta pode danificar o DNA das células da pele, podendo contribuir para o surgimento de lesões de câncer de pele, principalmente quando não se tem a resposta correta de defesa dos melanócitos. A seleção dos artigos aconteceu através das fontes de dados como as bases do Periódicos Capes, PubMed, Scielo e Google acadêmico, tendo como critério de exclusão os que fossem inferior ao ano de 2008. Obteve-se como conclusão deste trabalho que os protetores solares são as melhores opções na prevenção contra esta patologia até o momento.
\end{abstract}

Palavras-chave: CA de pele; Melanina; Proteção solar.

\begin{abstract}
The present study aimed to show the increase in the number of cases of skin cancer (CA), in addition, to bringing the main triggering factors of the disease. CA can be directly related to genetic and external factors. Sun exposure without proper care is identified as one of the main risk factors. Exposure to ultraviolet radiation can damage the DNA of skin cells and can contribute to the development of skin cancer lesions, especially when the correct melanocyte defense response is lacking. The selection of articles was based on data sources, such as the bases of Periódicos Capes, PubMed, Scielo, and Google academic, with exclusion criteria being those that were lower than the year 2008. In conclusion, this study reported that sunscreens are the best option to prevent this pathology until now.
\end{abstract}

Key Words: Skin CA; Melanin; Solar protection.

${ }^{1}$ Estudante do Curso de Mestrado de Ciências da Saúde e da Vida. Universidade Franciscana. E-mail: gabrielahmello1@gmail.com

${ }^{2}$ Francine Carla Cadoná. Doutora. Curso de Farmácia e Mestrado de Ciências da Saúde e da Vida. Universidade Franciscana. E-mail: fran.cine.bio@hotmail.com 


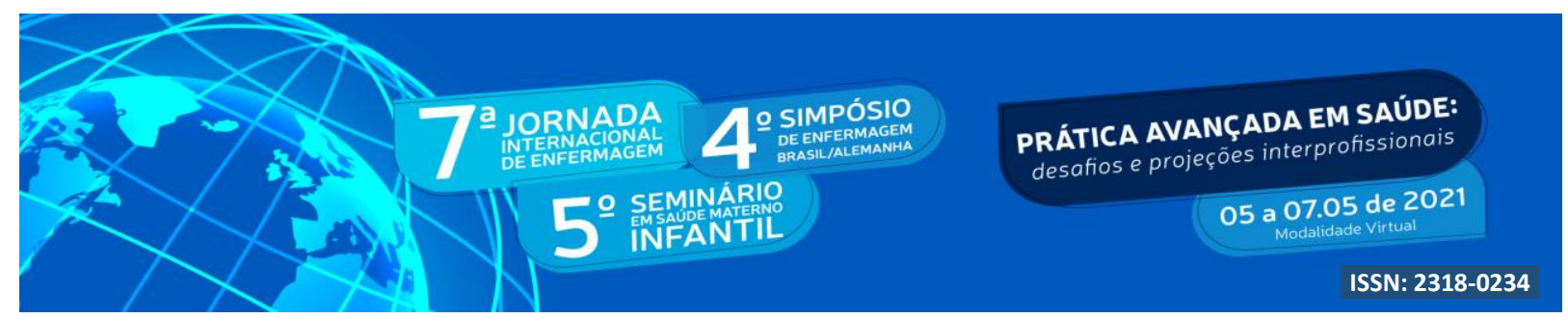

\section{INTRODUÇÃO}

O câncer é uma etiopatologia de causa multifatorial capaz de causar desordem celular. Ocorre por fatores genéticos ou externos, sendo estes ambientais ou por hábitos de vida. A nomenclatura "câncer" é usada para cem tipos de doenças, as quais tem como característica comum o crescimento celular desorganizado e acelerada conforme a figura 1, com caráter agressivo e ingovernável, capaz de rapidamente invadir órgãos e tecidos, processo denominado "metástase" (INCA, 2019).

Figura 1: Evolução tumoral frente aos fátores de risco

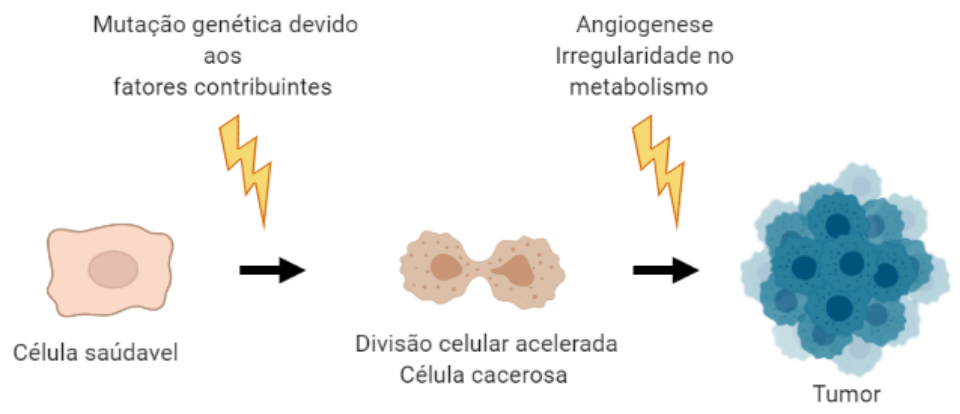

Fonte: Desenvolvida pelos autores.

Existem vários tipos de câncer, sendo seu nome dado conforme o local onde houve a alteração celular. Em casos onde a enfermidade tem início em tecidos epiteliais ou mucosas, dá-se o nome de carcinoma, quando ocorre inicialmente em cartilagens, músculos, ossos ou tecidos conjuntivos, denomina-se sarcoma (INCA, 2019).

Segundo dados do Instituto Nacional do Câncer (INCA) órgão brasileiro responsável por desenvolver e implementar políticas de controle e prevenção dessa enfermidada, os tipos de neoplasias que apresentaram maior incidência em 2015 foram os relacionados à pele, em um percentual de mais de $30 \%$ do total de casos esperados. Diante desses dados é evidentemente a necessidade de implementação de politicas de concientização para se ter um controle desta infermidade e redução do número de casos (INCA, 2019; MORAES; BEATRIZ; TIBÃES, 2017).

O Cârcer de pele é popularmente encontrado em pessoas com pele clara, o mesmo 


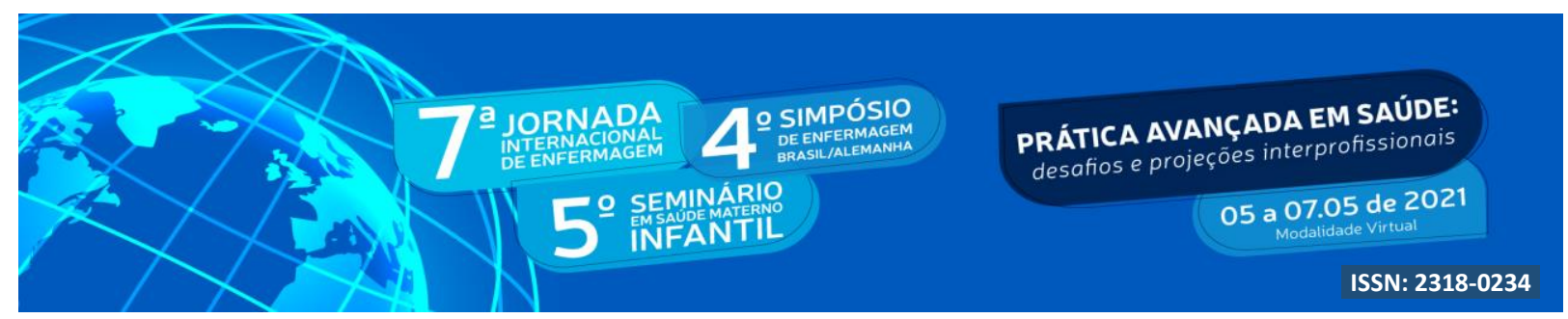

divide-se em duas variantes: não melanoma e melanoma (POPIM et al., 2008). O tipo nãomelanoma apresenta-se sob duas formas: carcinoma basocelular (CBC) e epidermóide ou espinocelular (CEC), os quais correspondem, respectivamente, a $80 \%$ e $20 \%$ dos casos na população brasileira e mundial. O diagnóstico precoce, ocorrente na maioria das vezes, traz por consequência um alto índice de cura (LAIKOVA et al., 2019; MORAES; BEATRIZ; TIBÃES, 2017).

Os CBCs apresentam um crescimento lento e, embora raramente evoluam para metástase, é localmente invasivo. Quando não tratado pode disseminar-se para outros tecidos e órgãos. Cerca de $80 \%$ dos diagnósticos são de ocorrências nas regiões de pescoço e cabeça, por serem áreas com maior exposição solar (FOLONI et al., 2018; POPIM et al., 2008).

O carcinoma epidermóide ou espinocelular (CEC) é mais propenso a se desenvolver em camadas profundas da pele, com isso, eleva o risco de metástase. Também são diagnosticados em regiões com maior exposição solar, podendo surgir em feridas de pele incuráveis e cicatrizes antigas. Considerado um tumor maligno, o qual deriva-se dos queratinócitos, é caracterizado pela proliferação atípica das células escamosas. Seu poder de invasão e destruição tecidual são maiores do que os causados pelo carcinoma basocelular. Os carcinomas epidermoides apresentam um potencial considerável de recorrência, o qual depende de algumas variáveis como tamanho do tumor, profundidade da lesão, sistema imunológico do paciente e localização anatômica (DIDONA et al., 2018).

O melanoma é o CA de pele de menor incidência, mas que apresenta maior taxa de mortalidade se diagnosticado metástase nos resultados e quando comparado ao nãomelanoma. Acomete preferencialmente indivíduos adultos e de pele clara, podendo também se manifestar em mucosas. O melanoma cutâneo é de grande magnitude devido à sua grande capacidade de metástase. Quando descoberto em estágios iniciais, pode ter bons resultados de sobrevivência do paciente (SANTOS; SOBRINHO; OLIVEIRA, 2018; SILVA; DIAS, 2018).

O câncer de pele melanoma representa $3 \%$ dos tumores malignos de pele. Sua incidência é inferior comparado com os outros cânceres de pele, porém apresenta a forma mais agressiva e letal devido a alta possibilidade de metástase (INCA, 2019). Tem origem nos melanócitos, células responsáveis pela produção de melanina, a qual é precursora da cor da pele e desempenha papel de proteção frente à exposição solar, atuando como barreira física 


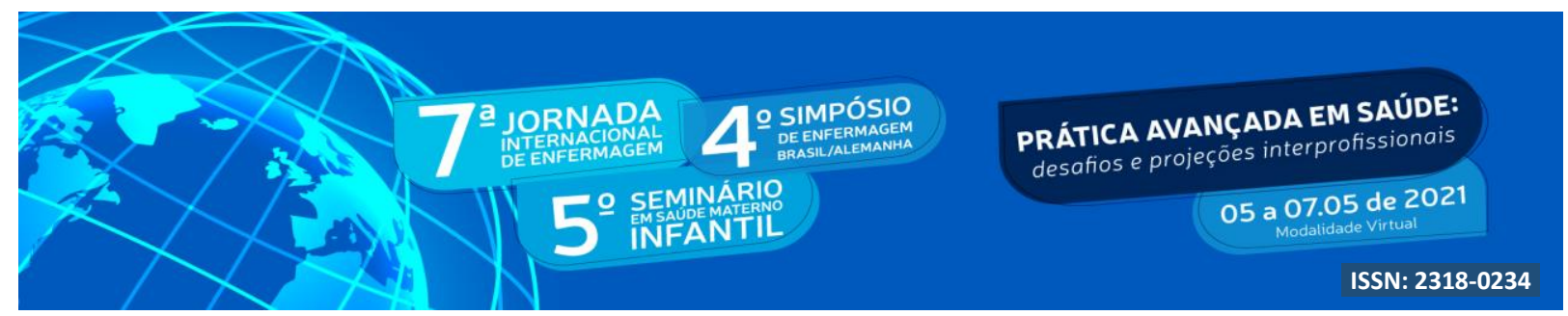

(CARVALHO et al., 2018; LAIKOVA et al., 2019).

Estudos apontam uma íntima relação entre o câncer de pele e exposição solar excessiva, em especial nos primeiros anos de vida, sendo os raios solares um dos principais fatores de risco para o desenvolvimento de CA de pele. Outros fatores de risco estão fortemente associados a esta patologia, como fatores genéticos, ambiente físico, hábitos de vida, quantidade de nevos, históricos de neoplasias malignas na família e cor da pele, sendo a caucasiana a mais pré-disposta a desenvolver a doença (BOMFIM et al., 2018; INCA, 2019).

\section{OBJETIVO}

O trabalho tem como objetico verificar a interfêrencia da qualidade dos hábitos de vida e os principais fatores de risco para o desenvolvimento do Câncer de pele.

\section{METODOLOGIA}

O trabalho trata-se de uma revisão da literatura. Foram utilizados como fonte de dados as bases de Periódicos Capes, PubMed, Scielo e Google acadêmico. Os artigos selecionados foram publicados de 2008 até 2021, tendo critérios de exclusão os com publicação anterior e que não fossem em relação ao tema. Os termos utilizados para a busca dos artigos estavam inseridos no próprio título, além das palavras-chaves. Os parâmetros para inclusão foram artigos que buscaram explorar os fatores de riscos frente ao cancêr de pele. Foram inclusos artigos em português, inglês e espanhol, estudos originais com os mais diversos delineamentos e estudos realizados em diferentes linhagens. Após análise do título e do resumo, a amostra deste artigo foi de vinte referências lidas na íntegra e extraídos os resultados mais importantes a fim de constar nesta revisão de literatura. Os resultados foram mostrados de maneira descritiva 


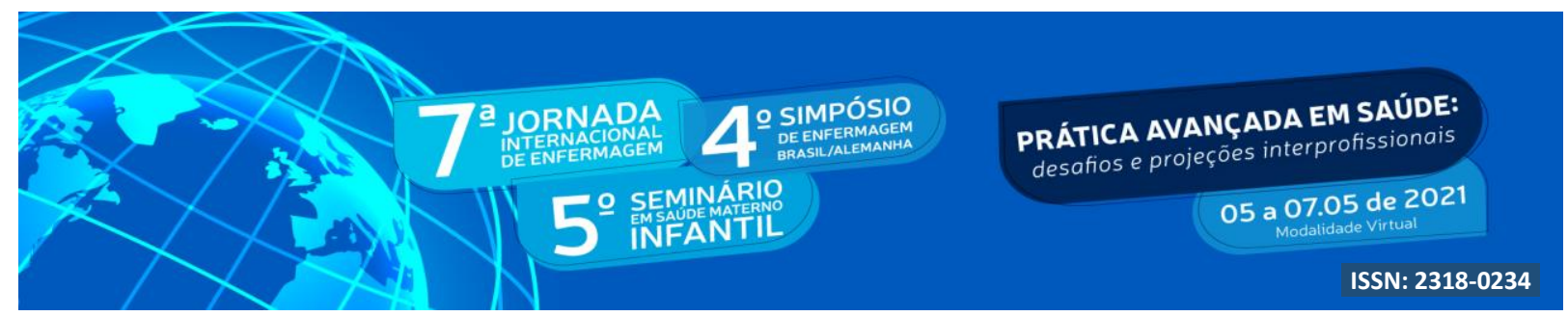

\section{RESULTADOS E DISCUSSÃO}

Ao pensarmos em câncer de pele temos de levar em considerações vários fatores que podem contribuir negativamente para a formação, desenvolvimento e contribuinte desta patologia. Essa neoplasia interfere diretamente na originalidade do DNA, dispondo de multiplicação celular acelerada e desgovernada, diferindo as novas células das originais (SANTOS; SOBRINHO; OLIVEIRA, 2018).

Vários fatores têm sido atribuídos como risco para o desenvolvimento dessa neoplasia, podendo ser genéticos e fatores externos. Os fatores genéticos estão fortemente relacionados a esta patologia, além da exposição ao sol, ambiente físico, hábitos de vida, quantidade de nevos, históricos de neoplasias malignas na família e cor da pele, sendo a caucasiana a mais pré-disposta a desenvolver a doença (INCA, 2019; SILVA; DIAS, 2018).

Estudos afirmam uma íntima relação entre o câncer de pele e exposição solar excessiva, em especial nos primeiros anos de vida, sendo os raios solares um dos principais fatores de risco para o desenvolvimento de CA de pele (BOMFIM et al., 2018; INCA, 2019). A radiação ultravioleta (UV) proveniente da luz solar tem efeitos nocivos à pele, e contribuem para a gênese das lesões de pele, quando exposta em excesso ou de forma inadequa, facilitam a mutação gênica e excercem efeitos supressores ao sistema imune cutâneo (DALCIN et al., 2021).

Os melanócitos presentes na pele, em nível basal, exercem importante função de proteção da mesma em resposta aos raios ultravioleta (UV), pois reduzem a penetração dessa radiação na epiderme, reduzindo possiveis danos. Esse efeito protetivo ocorre devido aos melanossomos, os quais ficam envoltos pelos melanócitos e queratinócitos, formando uma estrutura protetora para o DNA. Quando não ocorre esta proteção, o DNA das células pode mutar, consequentemente, iniciando um processo de carcinogênese. A radiação solar UV subdivide-se em 3 grupos com diferentes comprimentos de ondas: (1) UVA, com 315-400nm, (2) UVB com 280-315nm e (3) UVC com 100-280nm. A radiação UVA e UVB são as mais 


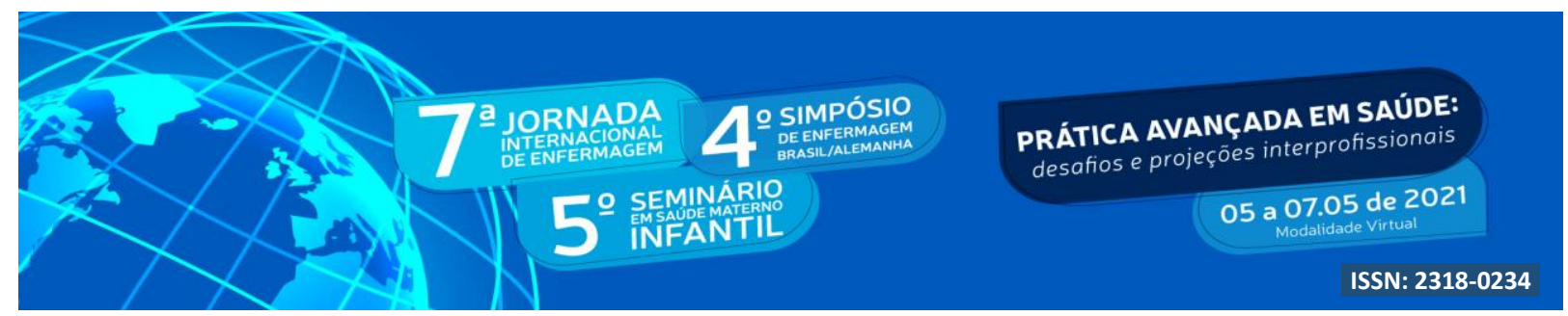

agressivas ao DNA das células da pele devido ao alto potencial de penetração de seus feixes de luz, tendo grande potencial carcinogênico (DALCIN et al., 2021; LEONARDI et al.,2018).

A faixa etária que está mais suscetível a esta alteração no DNA, e que também apresenta uma redução da função dos melanócitos são os idosos, o que permite a penetração dos raios, sem que os mesmo sejam barrados pela barreira de melanina. O envelhecimento afeta diretamente no processo de defesa imunológica do nosso organismo, diminuição da imunidade e células de Langerhans. Os jovens adultos também possuem chances de desenvolver esta patologia, quando expostos aos fatores de risco, ou causas genéticas, o que passa a ser um agravante para os idosos são as deficiências do sistema imune, além de carregarem consigo os danos ambientais desde sua infância (FRANCO et al., 2017).

A radiação UVB, embora não tenha poder de penetração tão grande quanto a UVA, é muito mais cancerígena em doses de energia significativamente menores, mas ambas têm grande poder mutagênico no DNA. A radiação UVC é majoritariamente bloqueada pela camada de ozônio, não tendo potencial mutagênico conforme figura 2 (SEEBODE; LEHMANN; EMMERT, 2016).

Figura 2: Penetração das diferentes radiações UV na pele.

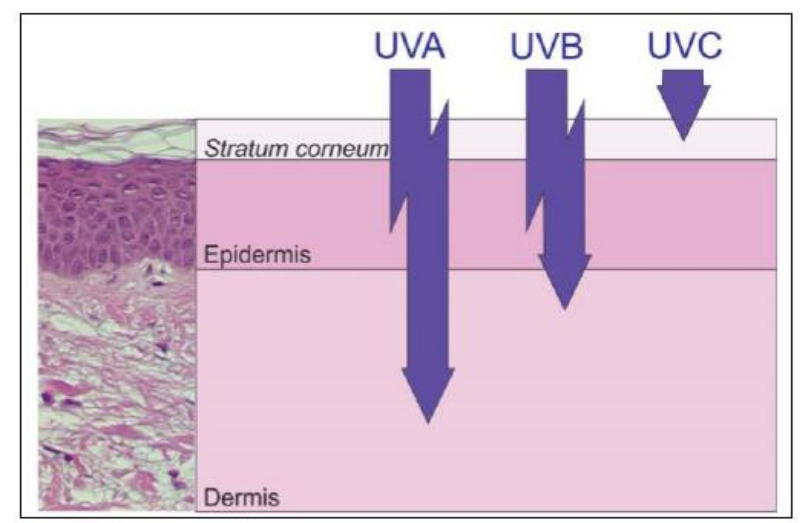

Fonte: Adaptado de SEEBODE; LEHMANN; EMMERT, 2016.

Como forma de prevenção, os protetores solares são as melhores opções. Após o diagnóstico positivo de CA de pele, a cirurgia é o mais indicado dos tratamentos. Radioterapia e quimioterapia podem servir de aliadas nos tratamentos cirúrgicos em casos onde ainda não tenha ocorrido metástase. Em casos de melanoma o tratamento é também realizado com 


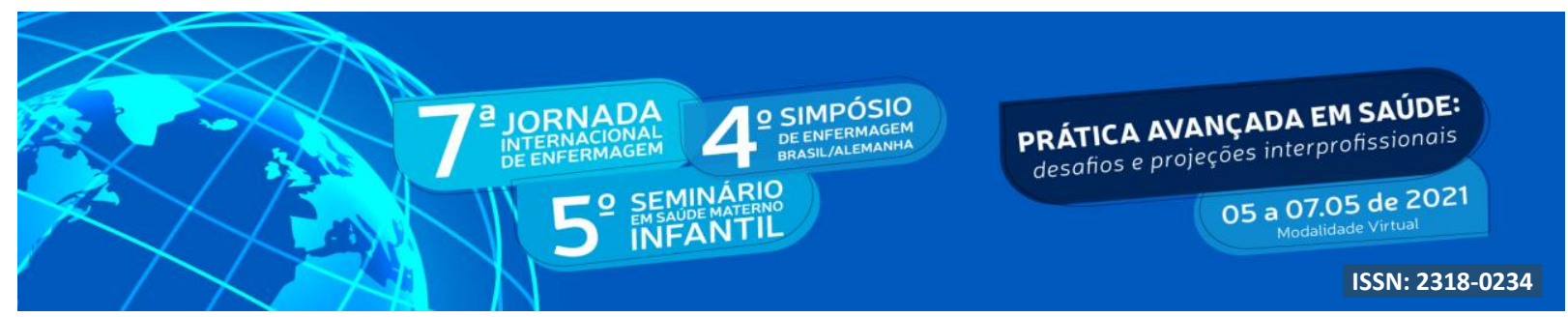

fármacos, que se mostram bastante eficazes na postergação da evolução da doença (DAHABRA et al., 2021; INCA, 2019).

\section{CONCLUSÃO}

De acordo com a literatura científica, a exposição solar sem a devida proteção pode ser um dos principais e se não mais importante dos contribuintes para o surgimento ou precipitante do câncer de pele. Levando em consideração a diminuição da resposta imune no processo do envelhecimento, é conclusivo que pacientes com maior idade estão mais prédispostos a esta doença. Entretanto, é necessário que ainda sejam realizadas pesquisas aos fatores de risco e também formas de prevenção a doença. 


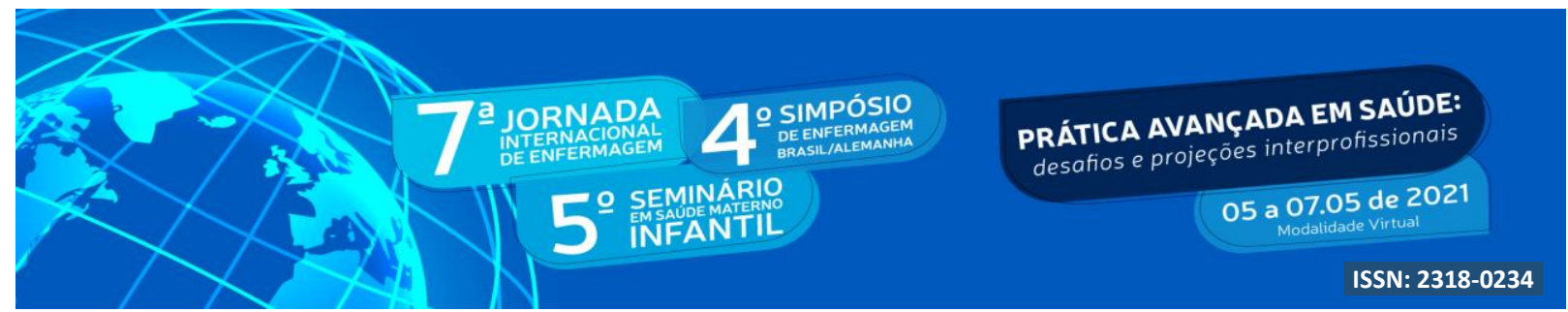

\section{REFERÊNCIAS}

BOMFIM, Simara Silva et al. Câncer De Pele : Conhecendo E Prevenindo a População Meta Skin Cancer: Knowing and Preventing Population. Revista de Divulgação Científica Sena Aires, $[s$. l. $]$, v. 7, n. 3, p. 255-259, 2018. Disponível em: http://revistafacesa.senaaires.com.br/index.php/revisa/article/view/329/240

CARVALHO, Juliana et al. Incidência de câncer de pele em ambulatório de dermatologia na Região Sul de São Paulo. [s. l.], v. 46, n. 1, p. 17-21, 2018.

DAHABRA, Layan et al. Sunscreens Containing Cyclodextrin Inclusion Complexes for Enhanced Efficiency : A Strategy for Skin Cancer Prevention. [s. l.], p. 1-22, 2021.

DALCIN, Mainara Meller et al. Câncer de pele em trabalhadores rurais: fotoexposição e orientação quanto a fatores de risco. Research, Society and Development, [s. l.], v. 10, n. 1, p. e15110111594, 2021. Disponível em: https://doi.org/10.33448/rsd-v10i1.11594

FOLONI, Ana Rafaela et al. Análise De Casos De Câncer De Pele Em Um Hospital Do Interior Paulista Analysis of Cases of Skin Cancer in a Hospital of Interior Paulista Análisis De Casos De Cáncer De Piel En Un Hospital Del Interior Paulista. [s. l.], v. 12, n. 2, p. 175-180, 2018.

FRANCO, Clayton et al. Fatores de risco do câncer de pele não melanoma em idosos no Brasil. Diagnóstico e Tratamento, [s. l.], v. 22, n. 61, p. 3-7, 2017.

INCA. [S. l.], 2019. Disponível em: https://www.inca.gov.br/o-que-e-cancer.

LAIKOVA, Kateryna V. et al. Advances in the understanding of skin cancer: Ultraviolet radiation, mutations, and antisense oligonucleotides as anticancer drugs. Molecules, [ $s$. l.], v. 24, n. 8, 2019. Disponível em: https://doi.org/10.3390/molecules24081516

LEONARDI, Giulia C. et al. Cutaneous melanoma: From pathogenesis to therapy (Review). International Journal of Oncology, [s. l.], v. 52, n. 4, p. 1071-1080, 2018. Disponível em: https://doi.org/10.3892/ijo.2018.4287

MORAES, Daniel Silva; BEATRIZ, Hanna; TIBÃES, Bacelar. Estudo Epidemiológico Do Câncer De Pele : Dados Do Instituto. [s. l.], 2017.

POPIM, Regina Célia et al. Câncer de pele: Uso de medidas preventivas e perfil demográfico de um grupo de risco na cidade de Botucatu. Ciencia e Saude Coletiva, [s. l.], v. 13, n. 4, p. 1331-1336, 2008. Disponível em: https://doi.org/10.1590/S1413$\underline{81232008000400030}$ 


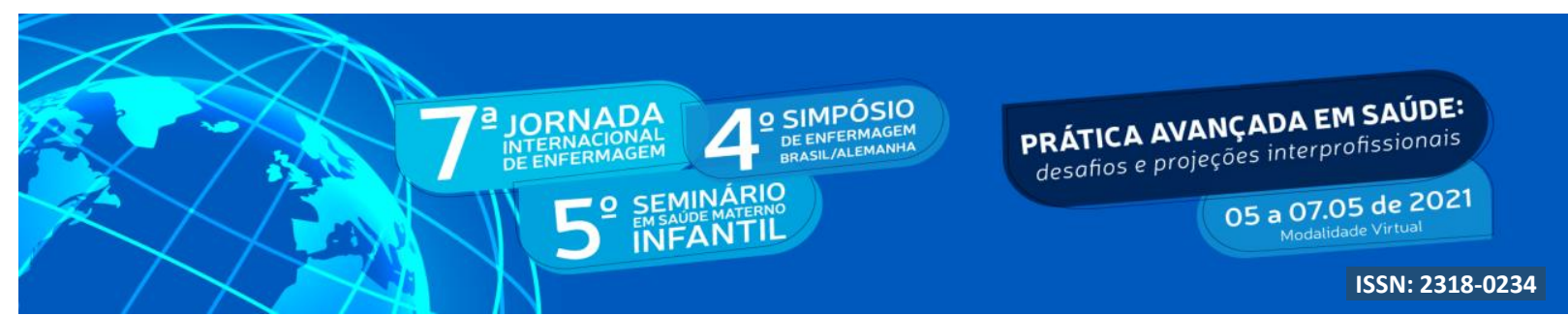

SANTOS, Sandra Oliveira; SOBRINHO, Raimaria Rodrigues; OLIVEIRA, Thainara Alves de. Importância do uso de protetor solar na prevenção do câncer de pele e análise das informações desses produtos destinados a seus usuários. Journal of Health \& Biological Sciences, [s. l.], v. 6, n. 3, p. 279, 2018. Disponível em: https://doi.org/10.12662/23173076jhbs.v6i3.1913.p279-285.2018

SEEBODE, Christina; LEHMANN, Janin; EMMERT, Steffen. Photocarcinogenesis and skin cancer prevention strategies. Anticancer Research, [s. l.], v. 36, p. 1371-1378, 2016.

SILVA, Ricardo Dias da; DIAS, Meyre Aparecida Inácio. Análise e incidência do melanoma cutâneo em um hospital de câncer localizado no Triângulo Mineiro. Revista Família, Ciclos de Vida e Saúde no Contexto Social, [s. l.], v. 6, p. 330, 2018. Disponível em: https://doi.org/10.18554/refacs.v6i0.2897 